\title{
Interaction potentials and transport properties of coinage metal cations in rare gases
}

\author{
Ahlam Yousef, Shraddha Shrestha, and Larry A. Viehland \\ Division of Science, Chatham University, Pittsburgh, Pennsylvania 15232, USA
}

\author{
Edmond P. F. Lee \\ School of Chemistry, University of Southampton, Highfield, Southampton SO17 1BJ, United Kingdom
}

Benjamin R. Gray, Victoria L. Ayles, and Timothy G. Wright

School of Chemistry, University of Nottingham, University Park, Nottingham NG7 2RD, United Kingdom

W. H. Breckenridge

Department of Chemistry, University of Utah, Salt Lake City, Utah 84112, USA

(Received 25 June 2007; accepted 30 July 2007; published online 16 October 2007)

\begin{abstract}
High-level $a b$ initio calculations are performed on the coinage metal cations $\left(\mathrm{Cu}^{+}, \mathrm{Ag}^{+}\right.$, and $\left.\mathrm{Au}^{+}\right)$ interacting with each of the rare gases $[\mathrm{Rg}(\mathrm{Rg}=\mathrm{He}$ to $\mathrm{Rn})]$. The $\mathrm{RCCSD}(\mathrm{T})$ procedure is employed, with basis sets being of approximately quintuple- $\zeta$ quality, but with the heavier species using relativistic effective core potentials. The interaction potentials are compared to experimental and theoretical data where they exist. In addition, transport coefficients for the mobility and diffusion of the cations in the rare gases are calculated. The latter have involved a rewriting of some of the programs used, and the required modifications are discussed. The mobility results indicate that, rather than being a rare occurrence, mobility minima may be common phenomena. Finally, a new estimate is put forward for the validity of zero-field mobilities in ion mobility spectrometry. ( 2007 American Institute of Physics. [DOI: 10.1063/1.2774977]
\end{abstract}

\section{INTRODUCTION}

We have been involved for several years in generating $a b$ initio potential energy curves of high accuracy for atomic ions interacting with the rare gases, and in testing them by comparison with spectroscopic, high-energy scattering and gaseous ion transport data. The spectroscopic data allow the potential energy curves to be assessed near the minima and at infinitely large separation (by comparison to long-range parameters and the dissociation energy). The scattering data allow the potential to be assessed at very short separations. To test the curve as a whole, however, the best approach appears to be a statistical comparison between mobility and diffusion coefficients calculated from the $a b$ initio potentials and experimental data taken over wide ranges of gas temperature and electric field strength.

To date, we have studied ${ }^{3} \mathrm{He}^{+}$and ${ }^{4} \mathrm{He}^{+},{ }^{1} \mathrm{Cl}^{-}$, the alkali metal cations, ${ }^{3-6} \mathrm{O}^{-},{ }^{7} \mathrm{I}^{-},{ }^{8} \mathrm{~S}^{-},{ }^{9} \mathrm{Hg}^{+}$and $\mathrm{Cd}^{+},{ }^{10} \mathrm{O}^{+},{ }^{11} \mathrm{~F}^{-},{ }^{12}$ $\mathrm{Br}^{-13},{ }^{13}$ and $\mathrm{Tl}^{+} .{ }^{14}$ Values calculated from our interaction potentials are in good to excellent agreement with experimental data where they exist, and in each case our potential was found either to be in agreement with the best potential available elsewhere or to be actually the best potential available. In some cases, we were also able to make a critical assessment of several experimental data sets available for the same ion-neutral system, and to conclude which were the more reliable. This encourages us to begin calculations for systems where there are no or more-limited experimental data, such as the singly charged coinage metal cations $\left(\mathrm{Cu}^{+}, \mathrm{Ag}^{+}\right.$, and $\mathrm{Au}^{+}$) interacting with the six rare gases. The limited spectroscopic data and previous ab initio studies will allow some assessment of the methods we employ, and consequently we can make some deductions regarding the reliability of the results.

\section{POTENTIAL ENERGY CURVES}

\section{A. Calculation details}

The coinage metal atoms have an outer electronic configuration of $n d^{10}(n+1) s^{1}$, arising from the extra stabilization afforded by the fully-filled $d$ shell. Consequently, the singlycharged cation has a closed-shell $d^{10}$ configuration. We performed a set of $a b$ initio calculations using the MOLPRO ${ }^{15}$ suite of programs. The potential energy curves were calculated point by point at the coupled cluster level of theory with single and double excitations and with noniterative correction for triple excitations, $\operatorname{CCSD}(\mathrm{T})$. The full counterpoise correction was employed at each point to correct for basis set superposition error.

The calculations were run with augmented, quintuple- $\zeta$ basis sets (aug-cc-pV5Z) for $\mathrm{He}, \mathrm{Ne}$, and $\mathrm{Ar}$. For $\mathrm{Kr}, \mathrm{Xe}$, and $\mathrm{Rn}$ we employed the small-core relativistic effective core potentials $^{16}$ (ECP) ECP10MDF, ECP28MDF, and ECP60MDF, respectively, with the associated aug-cc-pV5Z basis sets to describe the valence electrons. The $\mathrm{Cu}^{+}, \mathrm{Ag}^{+}$, and $\mathrm{Au}^{+}$ions were treated with similar effective core potentials, ${ }^{17}$ ECP10MDF, ECP28MDF, and ECP60MDF, respectively, and augmented with a designed valence basis set, as follows.

For copper, a Hartree-Fock calculation was carried out on $\mathrm{Cu}^{+}$employing an uncontracted $(19 s 13 p 15 d)$ basis set. 
The $\zeta$ values for this basis set were even tempered, with (center exponent, ratio) values as follows: $s(3.0,1.8), p(8.0$, $1.7)$, and $d(5.0,1.7)$. The coefficients from this calculation were used to define a contracted set of $[1 s 1 p 1 d]$ functions, which were then further augmented with three $g$ functions with $\zeta=2.4,0.6$, and 0.15 , with two $h$ functions with $\zeta=2.0$ and 0.1 , and with sets of even-tempered uncontracted functions as follows: seven $s(0.4,2.5)$, five $p(0.23,2.5)$, five $d$ $(0.6,2.5)$, and five $f(0.3,3.0)$. This basis set yields $\operatorname{RCCSD}(\mathrm{T})$ atomic ionization energies of $7.7295 \mathrm{eV}$ when only the $3 d$ and $4 s$ electrons were correlated, and $7.7265 \mathrm{eV}$ when the $3 s, 3 p, 3 d$, and $4 s$ electrons were correlated; both of these values are extremely close to the experimental value of $7.7264 \mathrm{eV}$, showing that the basis set is extremely accurate, and performs well with the large or small correlation space.

For silver, the same method yielded a $[1 s 1 p 1 d]$ set of functions based on the Hartree-Fock wave function of $\mathrm{Ag}^{+}$as calculated with a $(19 s 17 p 17 d)$ even-tempered basis set given by $s(1.6,1.8), p(1.7,1.6)$, and $d(1.6,1.6)$. These were then augmented in the $\mathrm{Ag}^{+}$-rare gas $(\mathrm{Rg})$ calculations by six $p$ functions with $\zeta=6.25,2.5,1.0,0.4,0.16$, and 0.064 , four $f$ functions with $\zeta=2.7,0.9,0.3$, and 0.1 , three $g$ functions with $\zeta=1.2,0.4$, and 0.1333 , two $h$ functions with $\zeta=0.9$ and 0.18 , and the following even-tempered functions: seven $s$ $(0.32,2.5)$ and five $d(0.4,2.5)$. With this basis set, we calculate $\operatorname{IE}(\mathrm{Ag})=7.4792 \mathrm{eV}$ when the $4 s 4 p 4 d$ electrons were correlated, with this improving to $7.5961 \mathrm{eV}$ when all nonECP electrons are correlated (cf. the experimental value of $7.5762 \mathrm{eV}$ ).

For gold, the $[1 s 1 p 1 d]$ contracted part of the basis set was obtained from a Hartree-Fock calculation on $\mathrm{Au}^{+}$with a $(19 s 17 p 13 d)$ even-tempered basis set given by $s(1.2,1.8), p$ $(1.0,1.8)$, and $d(1.0,1.8)$. This was then augmented by six $p$ functions with $\zeta=6.25,2.5,1.0,0.4,0.16$, and 0.064 , three $g$ functions with $\zeta=3.0,0.75$, and 0.1875 , two $h$ functions with $\zeta=1.2$ and 0.25 , and the following even-tempered functions: seven $s(0.8,2.5)$ and five $d(0.625,2.5)$. With this basis set, we calculate $\operatorname{IE}(\mathrm{Au})=9.0612 \mathrm{eV}$ when the $5 s 5 p 5 d$ electrons were correlated, with this improving to $9.1921 \mathrm{eV}$ when all non-ECP electrons are correlated (cf. the experimental value of $9.2257 \mathrm{eV}$ ).

For these species, decisions had to be made as to which orbitals were correlated in order to make the calculations tractable. This was not straightforward, since the orbitals of the rare gas atom and the metal cation overlapped in energy. Consequently, we considered each complex individually in order to decide on the correlation scheme to be employed.

For $\mathrm{Cu}^{+}-\mathrm{Rg}, \mathrm{Rg}=\mathrm{He}$ to $\mathrm{Ar}$, the $3 s, 3 p$, and $3 d$ electrons of $\mathrm{Cu}^{+}$were correlated, while for the $\mathrm{Rg}$ atoms the $1 s$ orbital of $\mathrm{Ne}$, and the $1 s, 2 s$, and $2 p$ orbitals of Ar were kept frozen.

For $\mathrm{Cu}^{+}-\mathrm{Kr}$, the $3 p$ electrons of $\mathrm{Cu}^{+}$are very close in energy to the $3 d$ orbitals of $\mathrm{Kr}$; thus, either both or neither set of the orbitals needs to be correlated. It turned out to be prohibitive to correlate both sets (which would have led to 34 electrons being correlated), and so for $\mathrm{Cu}^{+}-\mathrm{Kr}$, the $\mathrm{Kr} 4 s$ and $4 p$ electrons, and only the $\mathrm{Cu}^{+} 3 d$ electrons were correlated; this also precluded having to augment the basis set with tight $d$ functions for $\mathrm{Kr}$.
For $\mathrm{Cu}^{+}-\mathrm{Xe}$, similar considerations led to the $5 s$ and $5 p$ electrons of Xe and only the $3 d$ orbitals of $\mathrm{Cu}^{+}$to be correlated; and for $\mathrm{Cu}^{+}-\mathrm{Rn}$, the $6 s$ and $6 p$ electrons of $\mathrm{Rn}$ and the $3 d$ electrons of $\mathrm{Cu}^{+}$were included in the correlation treatment.

For $\mathrm{Ag}^{+}-\mathrm{Rg}$, for $\mathrm{Rg}=\mathrm{He}$ and $\mathrm{Ne}$, the $4 s, 4 p$, and $4 d$ electrons of $\mathrm{Ag}^{+}$were correlated; for $\mathrm{Ne}$, only the $1 s$ orbital was frozen.

For $\mathrm{Ag}^{+}-\mathrm{Rg}(\mathrm{Rg}=\mathrm{Ar}$ to $\mathrm{Rn})$, the $4 d$ electrons of $\mathrm{Ag}$ were correlated, and the outermost $n s$ and $n p$ electrons of $\mathrm{Rg}$, where $n=3,4,5$, and 6 for $\mathrm{Rg}=\mathrm{Ar}, \mathrm{Kr}, \mathrm{Xe}$, and $\mathrm{Rn}$, respectively.

Finally, the picture was very similar for $\mathrm{Au}^{+}-\mathrm{Rg}$. For $\mathrm{Au}^{+}-\mathrm{He}$ and $\mathrm{Au}^{+}-\mathrm{Ne}$, the $5 s, 5 p$, and $5 d$ electrons were correlated; only the $1 s$ orbital of $\mathrm{Ne}$ was frozen. For $\mathrm{Au}^{+}-\mathrm{Rg}$ $(\mathrm{Rg}=\mathrm{Ar}$ to $\mathrm{Rn})$, the $5 d$ electrons of $\mathrm{Au}$ were correlated, and the outermost $n s$ and $n p$ electrons of $\operatorname{Rg}$, where $n=3,4,5$, and 6 for $\mathrm{Rg}=\mathrm{Ar}, \mathrm{Kr}, \mathrm{Xe}$, and $\mathrm{Rn}$, respectively.

\section{B. Potential parameters}

The present potentials are presented in Figs. 1(a)-1(c) and the parameters characterizing our $a b$ initio potential curves are given in Table I. These are the separation $\sigma$, at which the interaction energy crosses through zero on the repulsive wall, the equilibrium separation $R_{e}$, at which the potential energy reaches its minimum value, and the depth of the potential well, $D_{e}$.

The data set can be summarized for each $\mathrm{M}^{+}-\mathrm{Rg}$ set, as we see similar trends down the $\mathrm{Rg}$ group in each case [refer to Table I and Figs. 1(a)-1(c)]. From $\mathrm{M}^{+}-\mathrm{He}$ to $\mathrm{M}^{+}-\mathrm{Ne}$ there is a slight increase in the zero and equilibrium energy distances and a deepening of the potential well. From $\mathrm{M}^{+}-\mathrm{Ne}$ to $\mathrm{M}^{+}-\mathrm{Ar}$ there is a decrease in the zero and equilibrium energy distances; this is most evident in the case of gold, where the $\mathrm{Au}^{+}-\mathrm{Ne}$ distance is larger than those of $\mathrm{Au}^{+}-\mathrm{Ar}$ and $\mathrm{Au}^{+}-\mathrm{Kr}$. The greatest deepening of the potential well occurs at Ar, with the depth of the $\mathrm{M}^{+}-\mathrm{Ar}$ potential well being 4.5-6.6 times greater than that of the corresponding $\mathrm{M}^{+}-\mathrm{Ne}$. This is mainly attributed to the large jump in the static electric dipole polarizability between neon $\left(0.396 \AA^{3}\right)$ and argon $\left(1.64 \AA^{3}\right)$. The increased polarizability leads to stronger, and so shorter, bond lengths and to greater binding energies. From $\mathrm{M}^{+}-\mathrm{Ar}$ to $\mathrm{M}^{+}-\mathrm{Rn}$ there are smooth increases in the zero energy and equilibrium energy distances and the depths of the potential wells. We compare these results to literature values in the subsections below.

\section{1. $\mathrm{Cu}^{+}-\mathrm{Rg}$}

Previous work on $\mathrm{Cu}^{+}-\mathrm{He}$ has been reported by Partridge et $a .^{18}$ using the modified coupled-pair functional (MCPF) approach. The potential reported in that work has a very similar $R_{e}$ value to the present result, differing by just $0.02 \AA$, but it has a significantly deeper well depth $D_{e}$ by $100 \mathrm{~cm}^{-1}$.

For $\mathrm{Cu}^{+}-\mathrm{Ne}$ the MCPF result is similar to our $R_{e}$ value, being $0.04 \AA$ larger. This time, however, their potential well is approximately $68 \mathrm{~cm}^{-1}$ shallower than ours. We can also compare our $\mathrm{Cu}^{+}-\mathrm{Ne}$ result with that of Froudakis et al., ${ }^{19}$ 

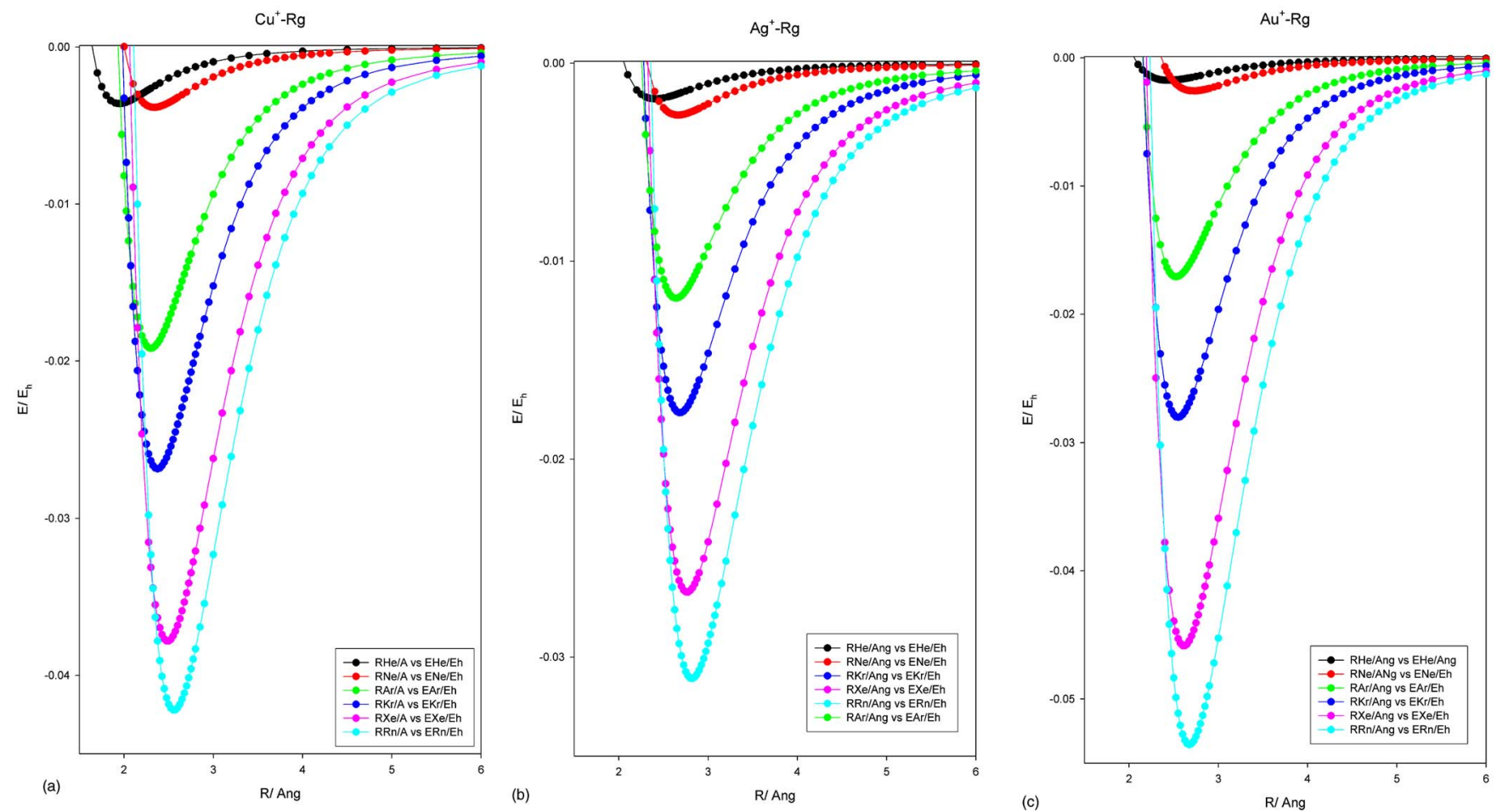

FIG. 1. (Color online) Potential energy curves for the (a) $\mathrm{Cu}^{+}-\mathrm{Rg}$, (b) $\mathrm{Ag}^{+}-\mathrm{Rg}$, and (c) $\mathrm{Au}^{+}-\mathrm{Rg}$ systems (curves in the order $\mathrm{Rg}=\mathrm{He}$ to $\mathrm{Rn}$ from top to bottom). Curves are calculated at the CCSD(T)/aug-cc-pV5Z level of theory. See text for details.

who used density functional theory (DFT) employing the B3LYP correlation function with $6-311 \mathrm{G}^{*}$ basis sets. Their value for $R_{e}$ is $0.18 \AA$ shorter than ours, and their value of $D_{e}$ is greater by almost $1200 \mathrm{~cm}^{-1}$, which is almost 2.4 times as large. It is unclear why this difference is so large-especially since, for $\mathrm{Cu}^{+}-\mathrm{Ar}$, the agreement is much better (vide infra).

$\mathrm{Cu}^{+}-\mathrm{Ar}$ seems to have the largest number of literature values to which to compare; this could be partly due to interest in spectroscopic studies of argon interactions with matrix-isolated transition metal atoms in the 1970s. References to this work can be found in Hammond et al. ${ }^{20}$ who presented unrestricted Hartree-Fock results which are, not surprisingly, vastly different from our highly correlated results. They calculate an $R_{e}$ value $0.32 \AA$ greater than the present result and the uncorrelated method underestimates the well depth by over $2600 \mathrm{~cm}^{-1}$. Although a number of $\mathrm{M}^{+}-\mathrm{Ar}$ species were considered in Ref. 20 it was only for the $\mathrm{Cu}^{+}-\mathrm{Ar}$ complex that correlated calculations were performed, at the CISD level with the inclusion of Davidson's correction. As may be seen in Table I, there is a large change in the potential parameters upon inclusion of some electron correlation, as was mentioned previously. ${ }^{18}$ The bond length shortens by $0.1 \AA$ and the binding energy increases by over $2100 \mathrm{~cm}^{-1}$, yet is still $500 \mathrm{~cm}^{-1}$ lower than the present value; this indicates that the demands on correlation within this system are quite stringent.

We can also compare our $\mathrm{Cu}^{+}-\mathrm{Ar}$ results with those of Partridge $e t$ al. ${ }^{18}$ Their $R_{e}$ value is slightly greater than ours but their $D_{e}$ value is significantly lower by nearly $1000 \mathrm{~cm}^{-1}$. Surprisingly, the DFT results of Froudakis et al. ${ }^{19}$ show good agreement with our $R_{e}$, with the $D_{e}$ value being much closer than that of Partridge et al. ${ }^{18}$ and, interestingly, much closer than was the case for $\mathrm{Cu}^{+}-\mathrm{Ne}$, mentioned above.

For this system we also have other $\operatorname{CCSD}(\mathrm{T})$ results with which to compare. Shen and BelBruno ${ }^{21}$ employed a $6 s 5 p 3 d 3 f / 5 s 5 p 3 d 2 f$ basis set with added $3 s 2 p 2 d$ bond functions. The agreement between that study and our own is very good, with near-identical bond lengths and very close agreement between the $D_{e}$ values. The agreement confirms that this species demands a good account of electron correlation, together with a basis set that is able to describe this.

Moving on to $\mathrm{Cu}^{+}-\mathrm{Kr}, \mathrm{CCSD}(\mathrm{T})$ results are provided by Shen and BelBruno, ${ }^{21}$ where again essentially perfect agreement is found for $R_{e}$. However, the agreement is not quite so good for $D_{e}$, with their value being just over $250 \mathrm{~cm}^{-1}$ (just under $5 \%$ ) higher than ours. We deduce that the differences must lie in the slightly different basis sets. Bauschlicher et al. $^{22}$ again employed the MCPF approach and obtained values of $R_{e}$ and $D_{e}$ that are longer and significantly smaller than those presented here. The good agreement between the present study and that of Ref. 21 suggests that the results from the MCPF study are not as reliable.

For $\mathrm{Cu}^{+}-\mathrm{Xe}$ we have only one set of results with which to compare. Results obtained ${ }^{23}$ by the coupled-electron pair approximation method produce a potential which has an equilibrium separation $0.14 \AA$ longer than ours and a well that is over $3000 \mathrm{~cm}^{-1}$ shallower.

Our results for $\mathrm{Cu}^{+}-\mathrm{Rn}$ appear to be the only ones available.

\section{2. $\mathbf{A g}^{+}-\mathbf{R g}$}

There is little literature on $\mathrm{Ag}^{+}$interacting with rare gases, with our results for $\mathrm{He}$ and $\mathrm{Ne}$ appearing to be the first 
TABLE I. Parameters of the coinage metal $\mathrm{Rg}$ interaction potentials.

\begin{tabular}{|c|c|c|c|c|c|}
\hline \multicolumn{2}{|c|}{ Potential } & \multirow{3}{*}{$\begin{array}{l}\text { Ref. } \\
\text { Present } \\
\text { Partridge }\end{array}$} & \multirow{2}{*}{$\frac{\sigma(\AA)}{1.64}$} & \multirow{2}{*}{$\frac{R_{e}(\AA)}{1.95}$} & \multirow{2}{*}{$\frac{D_{e}\left(\mathrm{~cm}^{-1}\right)}{790.28}$} \\
\hline \multirow[t]{17}{*}{$\mathrm{Cu}^{+}$} & $\mathrm{He}$ & & & & \\
\hline & & & & 1.97 & 887.31 \\
\hline & $\mathrm{Ne}$ & Present & 2.00 & 2.34 & 842.36 \\
\hline & & Partridge et al. (Ref. 18) & & 2.38 & 774.38 \\
\hline & & Froudakis et al. (Ref. 19) & & 2.16 & 2016.6 \\
\hline & Ar & Present & 1.93 & 2.30 & 4211.36 \\
\hline & & Hammond et al. (Ref. 20) & & 2.62 & 1565 \\
\hline & & Hammond et al. (Ref. 20) & & 2.51 & 3710 \\
\hline & & Partridge et al. (Ref. 18) & & 2.37 & 3266.9 \\
\hline & & Froudakis et al. (Ref. 19) & & 2.29 & 3952.6 \\
\hline & & Shen and BelBruno (Ref. 21) & & 2.31 & 4154.2 \\
\hline & $\mathrm{Kr}$ & Present & 1.98 & 2.37 & 5890.35 \\
\hline & & Bauschlicher, Jr. et al. (Ref. 22) & & 2.46 & 4682 \\
\hline & & Shen and BelBruno (Ref. 21) & & 2.37 & 6146.7 \\
\hline & $\mathrm{Xe}$ & Present & 2.06 & 2.49 & 8301.07 \\
\hline & & Freitag et al. (Ref. 23) & & 2.63 & 5100 \\
\hline & $\mathrm{Rn}$ & Present & 2.11 & 2.56 & 9264.41 \\
\hline \multirow[t]{10}{*}{$\mathrm{Ag}^{+}$} & $\mathrm{He}$ & Present & 2.05 & 2.41 & 395.88 \\
\hline & $\mathrm{Ne}$ & Present & 2.31 & 2.66 & 575.44 \\
\hline & Ar & Present & 2.25 & 2.64 & 2607.29 \\
\hline & & Brock and Duncan (Ref. 24) & & & $>2500$ \\
\hline & $\mathrm{Kr}$ & Present & 2.28 & 2.68 & 3877.94 \\
\hline & & Brock and Duncan (Ref. 24) & & & $>2900$ \\
\hline & $\mathrm{Xe}$ & Present & 2.32 & 2.76 & 5864.03 \\
\hline & & Brock and Duncan (Ref. 24) & & & $>3900$ \\
\hline & & Freitag et al. (Ref. 23) & & 3.04 & 3070 \\
\hline & $\mathrm{Rn}$ & Present & 2.36 & 2.82 & 6822.02 \\
\hline \multirow[t]{13}{*}{$\mathrm{Au}^{+}$} & $\mathrm{He}$ & Present & 2.06 & 2.44 & 385.25 \\
\hline & & Pyykkö (Ref. 25) & & 2.75 & 214 \\
\hline & $\mathrm{Ne}$ & Present & 2.36 & 2.73 & 565.17 \\
\hline & & Pyykkö (Ref. 25) & & 2.90 & 419 \\
\hline & $\mathrm{Ar}$ & Present & 2.15 & 2.53 & 3745.39 \\
\hline & & Pyykkö (Ref. 25) & & 2.73 & 2355 \\
\hline & $\mathrm{Kr}$ & Present & 2.16 & 2.55 & 6155.49 \\
\hline & & Pyykkö (Ref. 25) & & 2.71 & 4113 \\
\hline & $\mathrm{Xe}$ & Present & 2.19 & 2.61 & 10063.00 \\
\hline & & Pyykkö (Ref. 25) & & 2.76 & 7340 \\
\hline & & Schröder et al. (Ref. 26) & & 2.57 & 10600 \\
\hline & & Pyykkö (Ref. 27) & & & 12500 \\
\hline & $\mathrm{Rn}$ & Present & 2.23 & 2.67 & 11753.90 \\
\hline
\end{tabular}

available. The estimated dissociation energy values of Brock and Duncan ${ }^{24}$ for the $\mathrm{Ag}^{+}-\mathrm{Ar}, \mathrm{Ag}^{+}-\mathrm{Kr}$ and $\mathrm{Ag}^{+}-\mathrm{Xe}$ species are in fair agreement $\left(\approx 100 \mathrm{~cm}^{-1}\right)$ with our value for $\mathrm{Ag}^{+}-\mathrm{Ar}$, but become increasingly too low as the rare gas group is descended. For $\mathrm{Ag}^{+}-\mathrm{Xe}$, there is a difference of almost $2000 \mathrm{~cm}^{-1}$. This difference is perhaps not that surprising when one considers that the experimental values were derived from an estimate of the ionization energy of the complex; each estimate, in turn, was arrived at from the fact that a two-photon process was enough to ionize the complexes and so are formally lower-limit values. Thus, the internal energy of the cation (formed following the photoionization) was not accounted for, and of course it is expected that $\mathrm{Ag}^{+}-\mathrm{Xe}$ would be more internally excited than the two complexes with the lighter $\mathrm{Rg}$ atoms, explaining the trend in the disagreement with the present results; unfavorable
Franck-Condon factors are also a possibility. The $\mathrm{Ag}^{+}-\mathrm{Xe}$ result for $D_{e}$ of Freitag et al. ${ }^{24}$ is lower than the present one by $3070 \mathrm{~cm}^{-1}$. This is a significantly greater difference than was found for $\mathrm{Cu}^{+}-\mathrm{Xe}$.

Our results for $\mathrm{Ag}^{+}-\mathrm{Rn}$ appear to be the only ones available.

Given the similarity in basis sets and methods used to the case of the $\mathrm{Cu}^{+}-\mathrm{Rg}$ species, it seems reasonable to assume that the reliability of the results is also similar. Again, citing the good agreement with the recent $\operatorname{CCSD}(\mathrm{T})$ study $^{21}$ and ours, each employing different basis sets, the evidence seems to point toward the reliability of the present calculations versus the previous theoretical results and the experimental estimates.

\section{3. $\mathrm{Au}^{+}-\mathrm{Rg}$}

For the $\mathrm{Au}^{+}-\mathrm{Rg}$ species, Pyykkö ${ }^{25}$ has presented the results of $\operatorname{CCSD}(\mathrm{T})$ calculations for $\mathrm{Rg}=\mathrm{He}$ to $\mathrm{Xe}$. In that work, the effects of relativity were examined in the case of $\mathrm{Au}^{+}-\mathrm{Xe}$, and it was shown that the inclusion of relativistic effects (via the pseudopotential employed) was significant, and we reiterate that relativistic ECPs are employed herein. For the $\mathrm{Au}^{+}-\mathrm{Rg}$ complexes, Pyykkö's results have greater $R_{e}$ and significantly lower $D_{e}$ values than ours, with the effect increasing toward Xe. From what we have ascertained with the lighter species, this is likely to be attributable to the smaller basis set used in Ref. 25 and perhaps to the optimization of our basis set parameters for the gold cation.

For $\mathrm{Au}^{+}-\mathrm{Xe}$ we can also compare to the later data of Schröder et al., ${ }^{26}$ who also employed the $\operatorname{CCSD}(\mathrm{T})$ procedure. The largest basis set they used was designated as basis $\mathrm{D}$, and it is the results with that basis set which are shown in Table I. These results are in much better agreement with the present work, suggesting that a large basis set is required for accurate results on these species. The results for $\mathrm{Au}^{+}-\mathrm{Xe}$ were used as a benchmark in the study of Schröder et al. ${ }^{26}$ in order to put the binding energies of other $\mathrm{Au}^{+}$complexes on an absolute scale, so any reevaluation of this quantity would mean that the other values must be updated accordingly. We have confirmed the very high $D_{e}$ value and low $R_{e}$ value calculated by Schröder et al. ${ }^{26}$ They suggested that there may be a "chemical" component (i.e., the Xe atom is acting as a Lewis base, donating electron density to $\mathrm{Au}^{+}$), and we concur with this likelihood; in addition, the high interaction energies for $\mathrm{Cu}^{+}-\mathrm{Xe}$ and $\mathrm{Ag}^{+}-\mathrm{Xe}$ suggest the possibility of incipient chemical bonding effects here as well (vide infra).

We also note that there has been a recent report of a DFT study on $\mathrm{Au}^{+}-\mathrm{Xe}$ by Pyykkö and Runeberg, ${ }^{27}$ where BP86/ cc-pVDZ calculations were performed, yielding $D_{e}$ $=150 \mathrm{~kJ} \mathrm{~mol}^{-1}\left(12500 \mathrm{~cm}^{-1}\right)$, significantly higher than the value obtained herein.

Our results for $\mathrm{Au}^{+}-\mathrm{Rn}$ appear to be the only ones available.

\section{Spectroscopy data}

Our $a b$ initio potential energy data were used as input to LeRoy's LEVEL ${ }^{28}$ program, from which we were able to calculate equilibrium nuclear separations, dissociation energies, 
TABLE II. Calculated spectroscopic constants in $\mathrm{cm}^{-1}$, with numbers in parentheses denoting the power of 10 (see text for details).

\begin{tabular}{|c|c|c|c|c|c|c|}
\hline System & & $D_{0}$ & $\omega_{e}$ & $\omega_{e} x_{e}$ & $B_{0}$ & $D_{J 0}$ \\
\hline \multirow[t]{2}{*}{$\mathrm{Cu}^{+}$} & $\mathrm{He}$ & & & & & \\
\hline & & 667.2 & 215.6 & 14.63 & 1.120 & $1.09(-04)$ \\
\hline \multirow[t]{2}{*}{ Partridge et al. (Ref. 18) } & & & 271 & & & \\
\hline & $\mathrm{Ne}$ & 728.6 & 119.9 & 4.65 & 0.199 & $2.35(-06)$ \\
\hline \multirow[t]{2}{*}{ Partridge et al. (Ref. 18) } & & & 88 & & & \\
\hline & $\mathrm{Ar}$ & 4112.2 & 199.5 & 2.51 & 0.129 & $2.23(-07)$ \\
\hline \multirow[t]{2}{*}{ Partridge et al. (Ref. 18) } & & & 193 & & & \\
\hline & $\mathrm{Kr}$ & 5799.6 & 182.9 & 1.48 & 0.082 & $6.82(-08)$ \\
\hline \multirow[t]{2}{*}{ Bauschlicher, Jr. et al. (Ref. 22) } & & & 153 & & & \\
\hline & $\mathrm{Xe}$ & 8210.3 & 182.3 & 1.02 & 0.063 & $3.12(-08)$ \\
\hline \multirow[t]{2}{*}{ Freitag et al. (Ref. 23) } & & & 131 & & & \\
\hline & $\mathrm{Rn}$ & 9173.4 & 182.5 & 0.90 & 0.060 & $2.62(-08)$ \\
\hline \multirow[t]{5}{*}{$\mathrm{Ag}^{+}$} & $\mathrm{He}$ & 321.4 & 127.2 & 10.16 & 0.709 & $7.83(-05)$ \\
\hline & $\mathrm{Ne}$ & 530.5 & 89.3 & 3.76 & 0.138 & $1.41(-06)$ \\
\hline & $\mathrm{Ar}$ & 2538.8 & 138.1 & 1.98 & 0.083 & $1.23(-07)$ \\
\hline & $\mathrm{Kr}$ & 3815.3 & 126.2 & 1.07 & 0.050 & $3.13(-08)$ \\
\hline & $\mathrm{Xe}$ & 5800.5 & 128.0 & 0.70 & 0.037 & $1.29(-08)$ \\
\hline \multirow[t]{2}{*}{ Freitag et al. (Ref. 23) } & & & 102 & & & \\
\hline & $\mathrm{Rn}$ & 6762.4 & 199.6 & 0.52 & 0.029 & $7.15(-09)$ \\
\hline $\mathrm{Au}^{+}$ & $\mathrm{He}$ & 317.3 & 121.9 & 9.57 & 0.682 & $8.12(-05)$ \\
\hline \multirow[t]{2}{*}{ Pyykkö (Ref. 25) } & & & 93 & & & \\
\hline & $\mathrm{Ne}$ & 523.6 & 83.4 & 3.34 & 0.123 & $1.14(-06)$ \\
\hline \multirow[t]{2}{*}{ Pyykkö (Ref. 25) } & & & 71 & & & \\
\hline & $\mathrm{Ar}$ & 3669.2 & 159.7 & 1.78 & 0.079 & $7.98(-08)$ \\
\hline \multirow[t]{2}{*}{ Pyykkö (Ref. 25) } & & & 123 & & & \\
\hline & $\mathrm{Kr}$ & 6081.7 & 148.3 & 0.91 & 0.044 & $1.57(-08)$ \\
\hline \multirow[t]{2}{*}{ Pyykkö (Ref. 25) } & & & 120 & & & \\
\hline & $\mathrm{Xe}$ & 9988.1 & 151.1 & 0.56 & 0.031 & $5.42(-09)$ \\
\hline Pyykkö (Ref. 25) & & & 129 & & & \\
\hline \multirow[t]{2}{*}{ Schröder (Ref. 26) } & & & 149 & & & \\
\hline & $\mathrm{Rn}$ & 11687.4 & 134.5 & 0.39 & 0.023 & $2.55(-09)$ \\
\hline
\end{tabular}

and rovibrational energy levels (we consider the most abundant isotope for each atom in all cases: ${ }^{63} \mathrm{Cu},{ }^{107} \mathrm{Ag},{ }^{197} \mathrm{Au}$, ${ }^{4} \mathrm{He},{ }^{20} \mathrm{Ne},{ }^{40} \mathrm{Ar},{ }^{84} \mathrm{Kr},{ }^{132} \mathrm{Xe}$, and $\left.{ }^{222} \mathrm{Rn}\right)$. The calculated spectroscopic parameters are given in Table II. The dissociation energy $D_{0}$ is given as computed, while the vibrational constants $\omega_{e}$ and $\omega_{e} x_{e}$ have been determined from the energies of the three lowest vibrational levels with rotational quantum number $J=0$. The rotational constant $B_{0}$ and the centrifugal distortion constant $D_{J 0}$ have been obtained from the three lowest rotational energy levels. In principle, these spectroscopic parameters can be used to gain insight into the bonding within these species: in particular, whether the interactions are "physical" or "chemical." Analyses such as those put forward by Breckenridge and co-workers ${ }^{29,30}$ can be used to compare the results of model potential calculations with actual results. Such analyses do, however, have to be undertaken with due consideration of all terms in the expansion of the interaction energy. Read and Buckingham ${ }^{31}$ have previously considered the interactions in $\mathrm{Au}^{+}-\mathrm{Rg}$ species; however, the analyses were performed on less reliable potentials than those presented herein, and so their conclusions must be treated with caution. ${ }^{29}$ In our future work, ${ }^{32}$ we shall consider the interactions in terms of the model potential of Bellert and Breckenridge, ${ }^{29}$ but such an analysis is outside the scope of the present paper.

\section{TRANSPORT CALCULATIONS}

In the present work we have computed the gaseous ion transport coefficients using old and new versions of the GRAMCHAR program ${ }^{33}$ (we consider the most abundant isotope for each $\mathrm{M}^{+}$in all cases, as noted above in Sec. II C; however, for each $\mathrm{Rg}$, a mixture of isotopes in the naturally occurring ratio was employed). There were three reasons for rewriting this program. First, for some systems, the original version produced a shoulder in the region of $E / n_{0}$, the ratio of the electric field strength to the gas number density, where the mobility was increasing rapidly toward a true minimum; this shoulder resulted from an accidental convergence, i.e., the third and fourth approximations were quite similar but true convergence did not occur until the fifth or higher approximation. Second, the original version had great difficulty when the mobility had a minimum as well as a maximum; minima had previously been considered rare, but they do occur in some of the systems considered in the present paper.

The final reason is that the original program was written for work stations with limited amounts of main memory and slow computational speed compared to present computers. Accordingly, the program avoided recalculating quantities by storing them and it avoided storing large amounts of data by 
restricting routine calculations to a maximum of four approximations of the kinetic theory upon which it was based. The original version of GRAMCHAR tried to get around these limitations by considering at each $E / n_{0}$ many combinations of the eight parameters upon which it was based: zero-order approximations to the ion drift velocity, temperatures parallel and perpendicular to the electric field, skewness, parallel and perpendicular kurtosis, and two correlation coefficients. It looked carefully for a combination of these parameters that rapidly converged to accurate values for all eight quantities and for the parallel and perpendicular diffusion coefficients, which in effect caused the program to wander around in parameter space.

The new program, called GC, stores fewer things, even at the risk of some repetitive calculation. On a Sun Ultra 5 with 128 Mbytes of main memory, it is able to reach the eighth approximation in the same amount of computing time as the previous version uses for the fourth approximation. On a Sun Blade 100 with 1024 Mbytes of memory, it can reach the tenth approximation before swapping into and out of mass storage becomes excessive. The program GC therefore gives transport coefficients that are generally more accurate than the older program, e.g., $0.01 \%$ for the mobility rather than $0.1 \%$ when both programs are supplied with transport cross sections that are accurate to within $0.01 \%$ at all collision energies. Copies of GC, which is written in FORTRAN and incorporates a large number of other changes of minor importance, may be obtained from viehland@chatham.edu.

Among the ion-atom systems of interest here, the most difficult for either GRAMCHAR or GC to handle was $\mathrm{Ag}^{+}$in $\mathrm{Kr}$, so an extensive discussion of our calculations for this system is in order. The $\mathrm{Ag}^{+}-\mathrm{Kr}$ potential described above was used with the program QVALUES ${ }^{34,35}$ to generate the first 30 transport cross sections with an accuracy of $0.01 \%$ over a range of collision energies from $10^{-9}$ to 10 hartree. When these cross sections were used with GRAMCHAR to calculate the transport properties at $300 \mathrm{~K}$, convergence was not achieved for $E / n_{0}$ above $120 \mathrm{Td}\left(1 \mathrm{Td}=10^{-21} \mathrm{~V} \mathrm{~m}^{2}\right)$. The criterion for convergence used in these calculations was for two successive approximations to agree within $0.1 \%$ for the mobility, $1.0 \%$ for the diffusion coefficients parallel and perpendicular to the electric field, and $3.0 \%$ for the other parameters characterizing the ion velocity distribution function. When the program GC was used with the same cross sections, nearly identical values were obtained below $120 \mathrm{Td}$ in considerably less computing time than with GRAMCHAR. These values are shown in Fig. 2.

We next used GC to compute the transport coefficients at higher $E / n_{0}$ using fixed orders of approximation and having the program note whether or not convergence was achieved within the limits listed in the previous paragraph. The third approximation gave converged values between 120-160 and 210-375 Td, but these values clearly contained the mobility shoulder (see Fig. 2) found using GRAMCHAR. We conclude that the unphysical shoulder is not an artifact of either computer program but of the Gram-Charlier method ${ }^{33}$ used for solving the Boltzmann kinetic equation. Hence neither GRAMCHAR nor GC should be used in the third or lower ap-

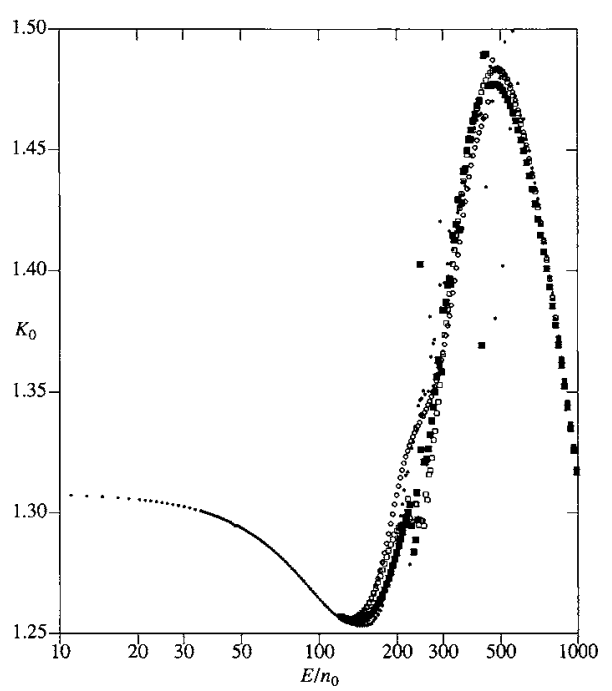

FIG. 2. Mobility in $\mathrm{cm}^{2} / \mathrm{V} \mathrm{s}$ of ${ }^{107} \mathrm{Ag}^{+}$ions in $\mathrm{Kr}$ at $300 \mathrm{~K}$ as a function of $E / n_{0}$ in Td. The dots below $120 \mathrm{Td}$ are converged values obtained with the program GRAMCHAR. The other values were obtained with the program GC using approximations 3 (open circles), 4 (open squares), 5 (filled squares), and 6 (stars)

proximation in regions of $E / n_{0}$ where the mobility is increasing rapidly.

The fourth approximation in GC gave converged values between 150-165 and 415-1100 Td, and the fifth and sixth approximations converged at a few more $E / n_{0}$ values above 120 Td. Note from Fig. 2, however, that in higher approximations there are occasional values of $E / n_{0}$ where the calculated mobility is clearly wrong. These points are all flagged by the program as being unconverged and they result from lack of convergence at the immediately preceding $E / n_{0}$ value, whose unconverged values for the eight parameters listed above were used to estimate values to begin the calculations at this $E / n_{0}$. We conclude that it is a poor strategy to continue brute-force calculations to increasingly higher orders of approximation. Instead, it is recommended that the calculations be repeated requesting a lower accuracy, as discussed below.

Figure 3 shows the results obtained in three passes. The first used $0.1 \%, 1.0 \%$, and $10 \%$ for the requested accuracy of the mobility, the ion diffusion coefficients and the other parameters, respectively. The mobility shoulder is evident. The second used $0.1 \%, 5.0 \%$, and $20 \%$, but the calculations were stopped at the fourth approximation, whether or not they had converged. Decreasing the requested accuracies of all of the parameters except the mobility is clearly ineffective. The third pass used accuracies of $1.0 \%, 15 \%$, and $30 \%$, which led to converged results at all $E / n_{0}$. It is notable that the converged mobilities agree with values calculated in other passes at $E / n_{0}$ values where the program indicated that those had converged.

Accuracies of $1 \%$ for the mobility and $15 \%$ for the diffusion coefficients are consistent with the typical accuracies of much of the existing experimental data on other systems. $^{36-39}$ If more accurate values are needed to match data of the highest quality, they can be obtained by considering one $E / n_{0}$ value at a time and manually adjusting the values of the eight parameters used to start the calculations 


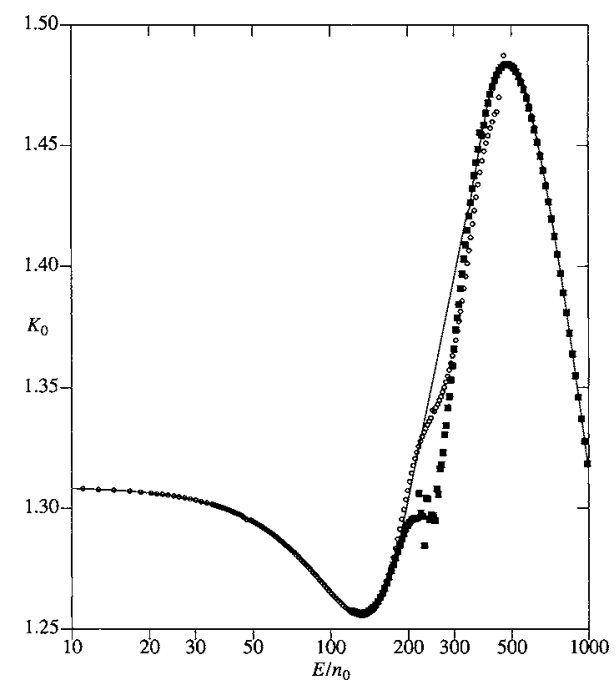

FIG. 3. Mobility in $\mathrm{cm}^{2} / \mathrm{V} \mathrm{s}$ of ${ }^{107} \mathrm{Ag}^{+}$ions in $\mathrm{Kr}$ at $300 \mathrm{~K}$ as a function of $E / n_{0}$ in $\mathrm{Td}$. The dots represent results obtained with the program the GC in passes 1 (open circles), 2 (filled squares), and 3 (solid curve). The passes are described in the text.

until a set is found that converges. Although initial estimates for the parameters can be taken from the converged results obtained with lower accuracy, this is a time-consuming task that cannot be easily automated. The results described in the remainder of this paper have not been computed in this way, and hence are only of moderate accuracy in some cases.

\section{FIELD-DEPENDENT MOBILITIES AND MOBILITY MINIMA}

We have calculated ion mobilities and diffusion coefficients for ${ }^{63} \mathrm{Cu}^{+},{ }^{107} \mathrm{Ag}^{+}$, and ${ }^{197} \mathrm{Au}^{+}$in each of the six rare gases. For each of the 18 systems we have made calculations over a very wide range of $E / n_{0}$ for gas temperatures $T_{0}$ of $100,200,300,400$, and $500 \mathrm{~K}$. For the systems involving $\mathrm{He}$, we have made additional calculations at $T_{0}=4.35 \mathrm{~K}$. All of these results have been placed in the gaseous ion transport database at Chatham University. ${ }^{40,41}$

In Figs. 4-6, we show the calculated mobilities at $300 \mathrm{~K}$ for each of the ions. The mobility reaches a maximum when $T_{0}$ and $E / n_{0}$ are such that the average collision energy is approximately equal to the well depth of the potential. Smaller values of $T_{0}$ and $E / n_{0}$ probe the potential primarily at larger separations, while those at higher values probe the repulsive wall of the potential.

The most interesting feature of Figs. 4-6 is the appearance of a mobility minimum for Ar and the heavier rare gases. A mobility minimum has been observed for $\mathrm{O}^{+}$in $\mathrm{Ar}$ at room temperature. ${ }^{42}$ Model calculations, ${ }^{43}$ based on the $(n, 6,4)$ interaction potential, suggested that the uncommon behavior of the mobility arises when the $R^{-6}$ component of the long-range interaction is large. This situation does not tend to arise when the ion and neutral are closed shell atoms. Since few experiments have been performed for open-shell ions and all atomic gases are closed shell, it is not surprising that the mobility minimum for $\mathrm{O}^{+}$in $\mathrm{Ar}$ is often referred to as rare. Our recent work on the open shell $\mathrm{Cd}^{+}$and $\mathrm{Hg}^{+}$ions in the heavy rare gases, ${ }^{10}$ however, showed that mobility

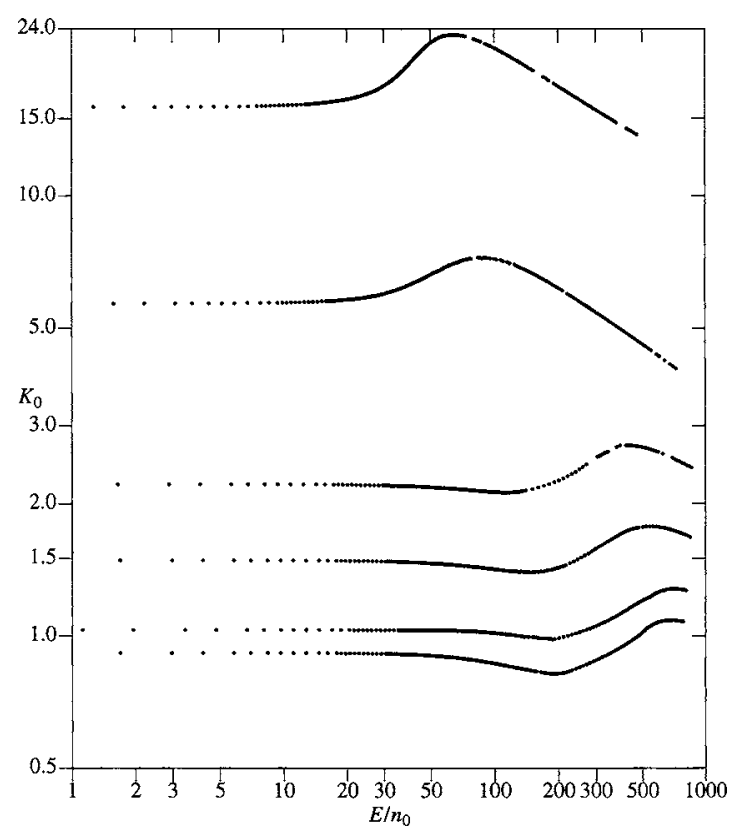

FIG. 4. Mobility in $\mathrm{cm}^{2} / \mathrm{V} \mathrm{s}$ of ${ }^{63} \mathrm{Cu}^{+}$ions in the rare gases at $300 \mathrm{~K}$ as a function of $E / n_{0}$ in Td. From top to bottom the results correspond to $\mathrm{He}, \mathrm{Ne}$, $\mathrm{Ar}, \mathrm{Kr}, \mathrm{Xe}$, and Rn.

minima are indeed found in other systems. The present results affirm that mobility minima are, in addition, likely to be somewhat common for heavier closed-shell ions.

To explore further the mobility minimum, we have plotted in Fig. 7 the mobility of $\mathrm{Ag}^{+}$in $\mathrm{Ar}$ for the five gas temperatures used in our calculations. Clearly the mobility minimum becomes more pronounced, relative to the zerofield mobility, as the temperature decreases. It is not surprising, therefore, that even the systems that do not have a minimum in Figs. 4-6 exhibit one at lower values of $T_{0}$.

In Ref. 10 we proposed "a rule of thumb," which stated that if the $R^{-4}$ potential (sometimes referred to as the polar-

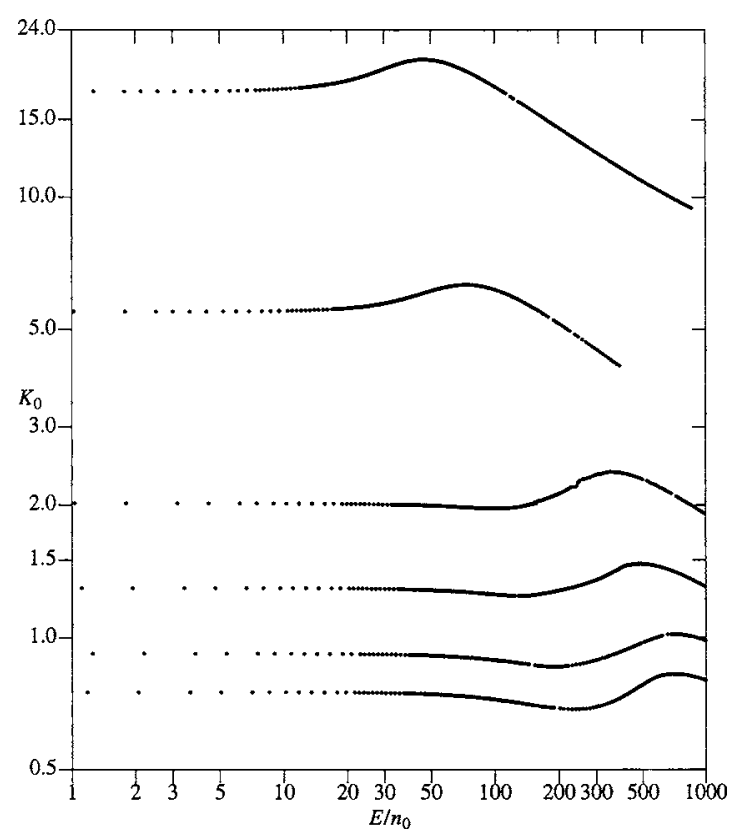

FIG. 5. Same as Fig. 3 for ${ }^{107} \mathrm{Ag}^{+}$ions. 


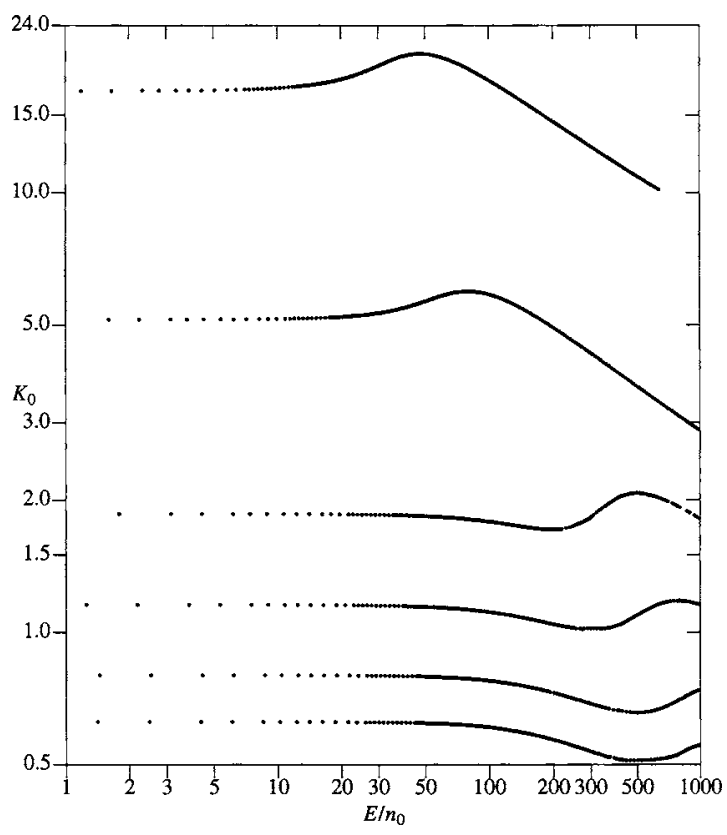

FIG. 6. Same as Fig. 3 for ${ }^{197} \mathrm{Au}^{+}$ions.

ization potential $V_{\mathrm{pol}}$ or the ion-induced dipole potential) crossed the full intermolecular potential on the repulsive wall, then we would expect to see a mobility minimum. That rule of thumb was deduced from our observations at $300 \mathrm{~K}$. The present work indicates that a caveat is that there is likely a temperature at which a mobility minimum theoretically exists for all ionic systems, but it is possible that it may be below the condensation temperature of the bath gas. We say this because there will always be higher-order terms contributing to the true intermolecular potential, ensuring that for large $R$, the curve will lie below the $V_{\mathrm{pol}}$ potential. To exemplify this, we show mobility plots for $\mathrm{Cu}^{+}-\mathrm{He}$ at 300,200 , 100, and $4.35 \mathrm{~K}$ in Fig. 8. As may be seen, there is a small

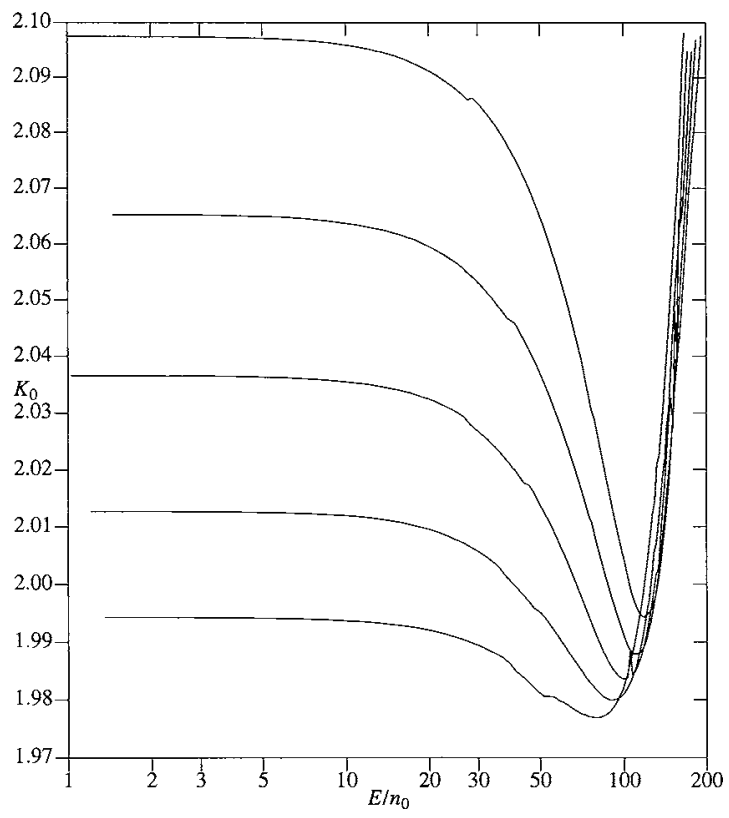

FIG. 7. Mobility in $\mathrm{cm}^{2} / \mathrm{V} \mathrm{s}$ of ${ }^{107} \mathrm{Ag}^{+}$ions in $\mathrm{Ar}$ at different temperatures as a function of $E / n_{0}$ in Td. From top to bottom the results correspond to $T_{0}$ values of $100,200,300,400$, and $500 \mathrm{~K}$.

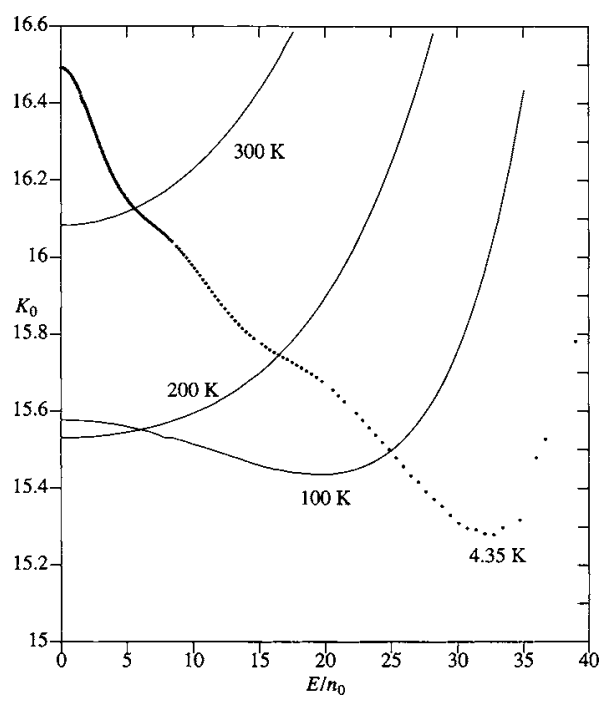

FIG. 8. Mobility in $\mathrm{cm}^{2} / \mathrm{V} \mathrm{s}$ of ${ }^{107} \mathrm{Cu}^{+}$ions in $\mathrm{He}$ at 100 and $4.35 \mathrm{~K}$ as a function of $E / n_{0}$ in Td.

mobility minimum at $100 \mathrm{~K}$, but this becomes much more clearly visible at $4.35 \mathrm{~K}$ when the long-range portions of the potential are being probed. The latter lie below the $R^{-4}$ potential which is, of course, the leading term in the interaction between $\mathrm{M}^{+}$and $\mathrm{Rg}$. In Fig. 9, we show the potential energy curves and the $V_{\text {pol }}$ curves for $\mathrm{Cu}^{+}-\mathrm{He}$ and $\mathrm{Cu}^{+}-\mathrm{Xe}$. As may be seen, the heavier species has $V_{\text {pol }}$ crossing the potential energy curve clearly on the repulsive wall, and this species demonstrates a mobility minimum even at $300 \mathrm{~K}$. For $\mathrm{Cu}^{+}-\mathrm{He}$, however, the crossing is very close to the minimum with the $V_{\text {pol }}$ curve lying just above the complete potential to long $R$, showing the small contribution of the $R^{-6}$ and higher terms. This is in line with our comments above, showing that a minimum does appear, but only at very low temperatures. Part of the rationale for the rule of thumb is the following. Not only must there be significant contributions from the $R^{-6}$ and higher terms, but also it is important that the repulsive interactions only become important at rather small $R$, so that these terms are still significant at $R_{e}$. Also if, as is likely the case for the $\mathrm{M}^{+}-\mathrm{Xe}$ cases described herein, there are incipi-

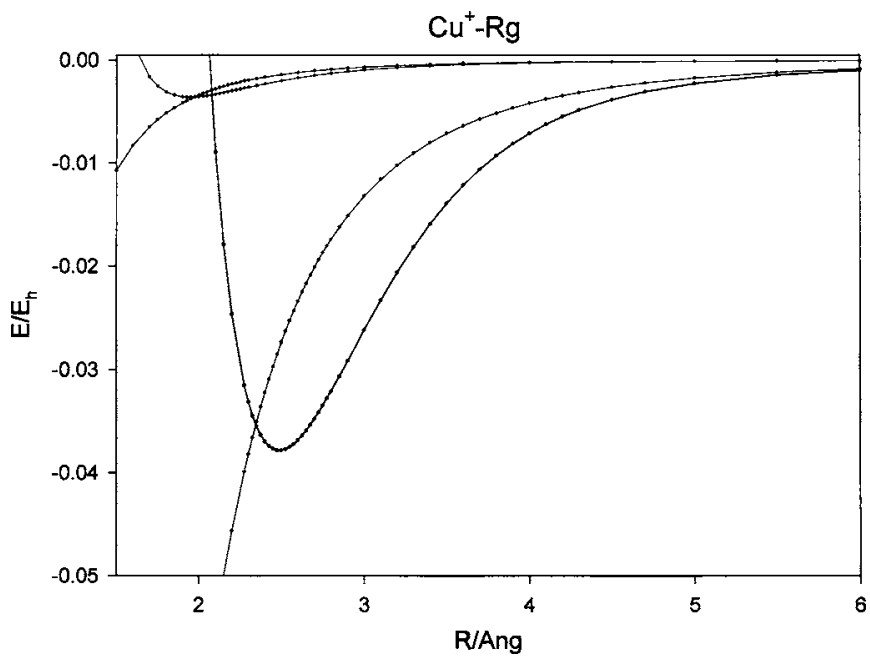

FIG. 9. Potential energy curves for $\mathrm{Cu}^{+}-\mathrm{He}$ (upper) and $\mathrm{Cu}^{+}-\mathrm{Xe}$ (bottom), and the corresponding $V_{\text {pol }}$ potentials. 


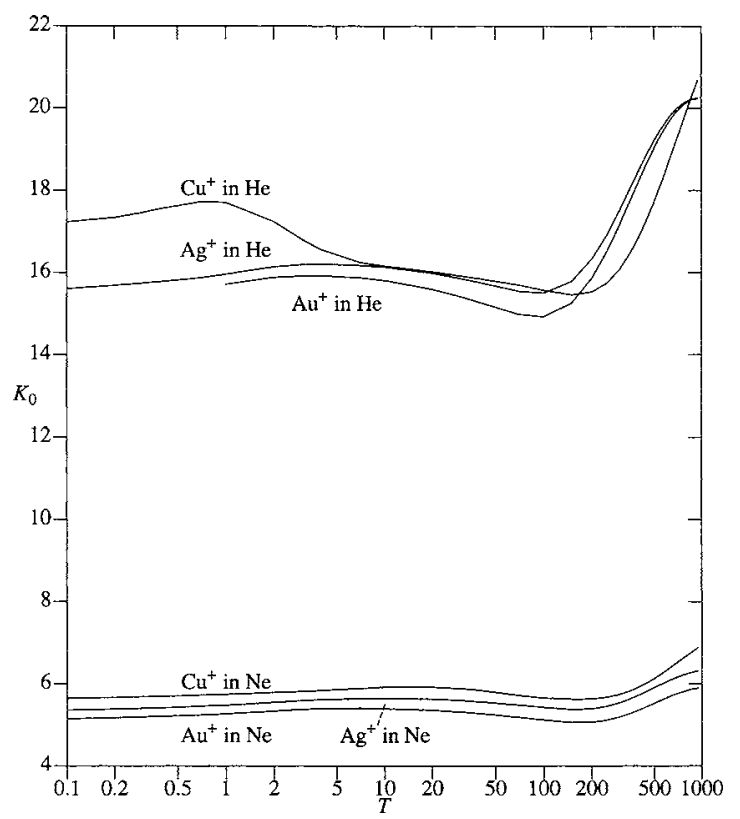

FIG. 10. Zero-field mobilities in $\mathrm{cm}^{2} / \mathrm{V}$ s of coinage metal anions in He and $\mathrm{Ne}$ as a function of gas temperature in $\mathrm{K}$.

ent chemical bonding effects, then these will also serve to move the interatomic potential below $V_{\text {pol }}$. The importance of the higher-order terms also indicates why electron correlation, and hence large, flexible basis sets, is required for these species.

\section{ZERO-FIELD MOBILITIES}

In recent years, there has been increased interest in ion mobility spectrometry (IMS), in which the differences in zero-field mobilities are used to separate gas-phase ions. ${ }^{44}$ We have used the program GC to calculate these values over a wide range of gas temperatures, as shown in Figs. 10 and 11. The important point to note is that, for many systems,

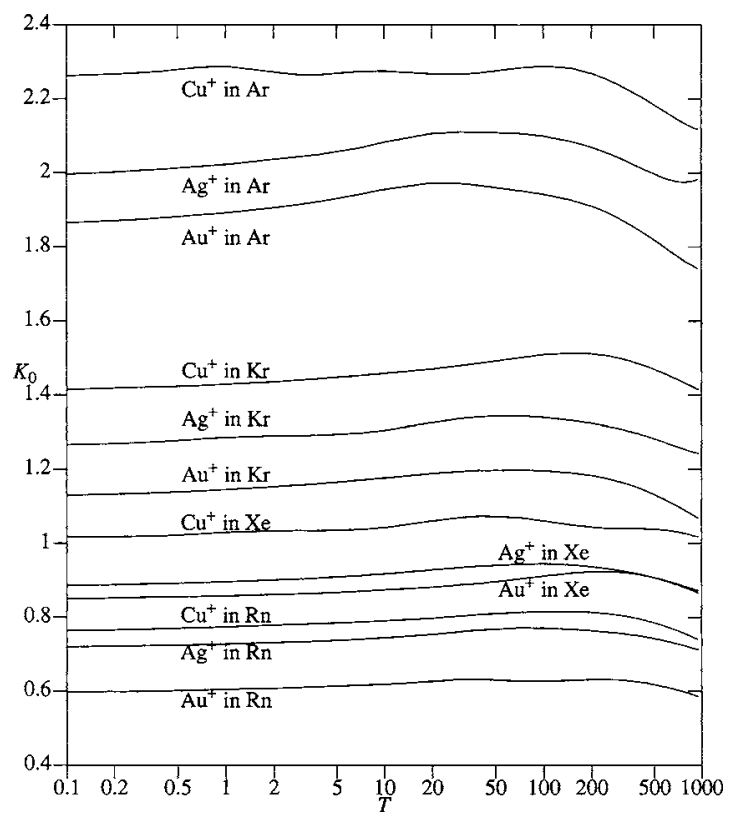

FIG. 11. Same as Fig. 10 for the heavy rare gases. changing the operating temperature of the IMS may change the zero-field mobilities by substantial amounts.

Another point of interest in IMS is what value of $E / n_{0}$ is low enough that the zero-field mobilities are close approximations to the actual mobility. The criterion often used ${ }^{44}$ in IMS was put forward in $1975,{ }^{45}$ but it suffers from a major weakness in that it is expressed in terms of the collision cross section, a quantity that can only be estimated. A more convenient criterion can be based on the well-known Wannier formula $^{46}$ for the average ion energy,

$$
\frac{3}{2} k_{B} T_{\text {ion }}=\frac{3}{2} k_{B} T_{0}+\frac{1}{2} m v_{d}^{2}+\frac{1}{2} M v_{d}^{2} .
$$

Here $k_{B}$ is Boltzmann's constant, $T_{\text {ion }}$ is the ion temperature characterizing the average ion energy in the laboratory frame of reference, $m$ is the ion mass, $M$ is the neutral mass, and $v_{d}$ is the average (steady-state) ion speed when moving through the gas under the influence of an electric field of magnitude $E$. The first term on the right-hand side of Eq. (1) is the thermal energy, i.e., the ion energy when zero-field conditions occur. The second term represents energy that the ions have gained from the electric field and is exhibited as directed motion along the direction of the field. The last term represents energy that the ions have gained from the electric field but, as a result of collisions, is now exhibited as random ion motion in the gas.

Low-field conditions must arise when the last two terms in Eq. (1) are small compared to the first. This leads to the result that

$$
v_{d} \ll\left(\frac{3 k_{B} T_{0}}{m+M}\right)^{1 / 2} .
$$

Now the ion mobility $K$ and standard mobility $K_{0}$ are defined by the expression

$$
v_{d}=K E=N_{0} K_{0}\left(E / n_{0}\right)
$$

where Loschmidt's constant, $N_{0}=2.6867773 \times 10^{25} \mathrm{~m}^{-3}$, is the number density of an ideal gas at standard temperature and pressure. Hence we are led to the low-field criterion that

$$
\frac{E}{n_{0}} \ll \frac{1}{N_{0} K_{0}}\left(\frac{3 k_{B} T_{0}}{m+M}\right)^{1 / 2} .
$$

For ${ }^{107} \mathrm{Ag}^{+}$ions in $\mathrm{Kr}$ at $300 \mathrm{~K}$, Fig. 11 shows that the zero-field mobility is $K_{0}=1.3088 \mathrm{~cm}^{2} / \mathrm{V} \mathrm{s}$. Then Eq. (4) implies that low-field conditions arise when $E / n_{0}$ is much less than $56.33 \mathrm{Td}$. We see from Figs. 2 and 3 that the mobility at $56 \mathrm{Td}$ is $1.2910 \mathrm{~cm}^{2} / \mathrm{V} \mathrm{s}$, which differs from the zero-field value by $1.4 \%$. If we somewhat arbitrarily choose to use $20 \%$ of the value obtained from the right-hand side of Eq. (4), i.e., $11.27 \mathrm{Td}$, the difference between the low-field and zero-field mobilities decreases to a negligible $0.05 \%$. We therefore recommend the use of

$$
\frac{E}{n_{0}}=\frac{1}{5 N_{0} K_{0}}\left(\frac{3 k_{B} T_{0}}{m+M}\right)^{1 / 2}
$$

as an upper bound for the $E / n_{0}$ value at which the zero-field mobilities in Figs. 10 and 11 may be used in interpreting IMS data. 


\section{CONCLUSIONS}

We have presented interaction potentials for 18 systems: the three coinage metal cations interacting with each of the six rare gas atoms. This is the first time that the whole set of these potentials has been presented together at levels of theory which are directly comparable. These potentials agree well with a few recent $\operatorname{CCSD}(\mathrm{T})$ calculations in the cases where large basis sets are employed. Disagreements with other theoretical results can be traced to either the incomplete accounting for correlation energy and/or insufficiently large basis sets employed. The present work employs basis sets which are large and flexible enough to account for the correlation energy. We believe that the values of the potential parameters presented are the most accurate so far reported.

We have computed spectroscopic parameters and ion transport coefficients from our ab initio potentials, but there are minimal experimental data with which to compare. Based on previous results ${ }^{1-14}$ and assuming that the present interaction potentials are accurate, we expect that the ion mobilities reported here are accurate to within about $0.2 \%$. This is true both for the mobilities at fixed $T_{0}$ as a function of $E / n_{0}$ and for the zero-field mobilities as a function of $T_{0}$. Our calculations suggest that a mobility minimum may be a common result for polarizable atomic ions moving through the heavier rare gases, for which the repulsive interactions only become significant at rather small $R$, at least at low enough gas temperatures.

Lastly, we have put forward a recommendation for a new estimate of an upper bound for the $E / n_{0}$ value at which zerofield mobilities are useful in interpreting IMS data.

\section{ACKNOWLEDGMENTS}

The authors are grateful to the EPSRC for the award of computer time at the Rutherford Appleton Laboratories under the auspices of the Computational Chemistry Working Party (CCWP), which enabled these calculations to be performed. One of the authors (E.P.F.L.) is grateful to the Research Grant Council (RGC Grant No. PolyU 5003/04P) of the Hong Kong Special Administration Region for support. The research of three of the authors A. Y., S. S., and L. A. V. was supported by the U.S. National Science Foundation under Grant No. CHE-0414241. One of the authors (W.H.B.) would like to thank the University of Utah for a travel grant for a visit to the University of Nottingham. Professor P. Pyykkö is thanked for alerting us to Ref. 27.

${ }^{1}$ M. S. Lee, A. S. Dickinson, and L. A. Viehland, J. Phys. B 33, 5121 (2000)

${ }^{2}$ A. A. Buchachenko, R. V. Krems, M. M. Szczsniak, Y.-D. Xiao, L. A. Viehland, and G. Chaasfski, J. Chem. Phys. 114, 9919 (2001).

${ }^{3}$ J. Lozeille, E. Winata, L. A. Viehland, P. Soldán, E. P. F. Lee, and T. G. Wright, Phys. Chem. Chem. Phys. 4, 3601 (2002).

${ }^{4}$ J. Lozeille, E. Winata, L. A. Viehland, P. Soldán, E. P. F. Lee, and T. G. Wright, J. Chem. Phys. 119, 3729 (2003).

${ }^{5}$ L. A. Viehland, J. Lozeille, P. Soldán, E. P. F. Lee, and T. G. Wright, J. Chem. Phys. 121, 341 (2004).

${ }^{6}$ H. L. Hickling, L. A. Viehland, D. T. Shepherd, P. Soldán, E. P. F. Lee, and T. G. Wright, Phys. Chem. Chem. Phys. 6, 423 (2004).

${ }^{7}$ L. A. Viehland, R. Webb, E. P. F. Lee, and T. G. Wright, J. Chem. Phys. 122, 114302 (2005)
${ }^{8}$ A. A. Buchachenko, T. V. Tscherbul, J. Klos, M. M. Szczesniak, G. Chalasinski, R. Webb, and L. A. Viehland, J. Chem. Phys. 122, 194311 (2005).

${ }^{9}$ T. G. Wright and L. A. Viehland, Chem. Phys. Lett. 420, 24 (2006).

${ }^{10}$ E. Qing, L. A. Viehland, E. P. F. Lee, and T. G. Wright, J. Chem. Phys. 124, 044316 (2006).

${ }^{11}$ D. M. Danailov, R. Brothers, L. A. Viehland, R. Johnsen, T. G. Wright, and E. P. F. Lee, J. Chem. Phys. 125, 084309 (2006).

${ }^{12}$ B. R. Gray, T. G. Wright, E. L. Wood, and L. A. Viehland, Phys. Chem. Chem. Phys. 8, 2752 (2006).

${ }^{13}$ A. A. Buchachenko, J. Klos, M. M. Szczesniak, G. Chalasinski, B. R. Gray, T. G. Wright, E. L. Wood, L. A. Viehland, and E. Qing, J. Chem. Phys. 125, 064305 (2006).

${ }^{14}$ B. R. Gray, E. P. F. Lee, A. Yousef, S. Shrestha, L. A. Viehland, and T. G. Wright, Mol. Phys. 104, 3237 (2006).

${ }^{15}$ H.-J. Werner, P. J. Knowles, J. Almlöf et al., MOLPRo. The CCSD treatment is described in C. Hampel, K. Peterson, and H. J. Werner, Chem. Phys. Lett. 190, 1 (1992).

${ }^{16}$ K. A. Peterson, D. Figgen, E. Goll, H. Stoll, and M. Dolg, J. Chem. Phys. 119, 11113 (2003).

${ }^{17}$ D. Figgen, G. Rauhut, M. Dolg, and H. Stoll, Chem. Phys. 311, 227 (2005).

${ }^{18}$ H. Partridge, C. W. Bauschlicher, Jr., and S. R. Langhoff, J. Phys. Chem. 96, 5350 (1992).

${ }^{19}$ G. E. Froudakis, M. Muhlhauser, S. C. Farantos, A. Sfounis, and M. Velegrakis, Chem. Phys. 280, 43 (2002).

${ }^{20}$ B. L. Hammond, W. A Lester, Jr., M. Braga, and C. Taft, Phys. Rev. B 41, 10447 (1990).

${ }^{21}$ Y. Shen and J. J. BelBruno, J. Phys. Chem. A 109, 10077 (2005).

${ }^{22}$ C. W. Bauschlicher, Jr., H. Partridge, and S. R. Langhoff, J. Chem. Phys. 91, 4733 (1989).

${ }^{23}$ A. Freitag, Ch. Van Wullen, and V. Staemmler, Chem. Phys. 192, 267 (1995).

${ }^{24}$ L. R. Brock and M. A. Duncan, J. Chem. Phys. 103, 9200 (1995).

${ }^{25}$ P. Pyykkö, J. Am. Chem. Soc. 117, 2067 (1995).

${ }^{26}$ D. Schröder, H. Schwarz, J. Hrusak, and P. Pyykkö, Inorg. Chem. 37, 624 (1998).

${ }^{27}$ P. Pyykkö and N. Runeberg, Chem. Asian J. 1, 623 (2006).

${ }^{28} \mathrm{R}$. J. LeRoy, LEVEL 7.2, A computer program for solving the radial Schrödinger equation for bound and quasibound levels and calculating various values and matrix elements. University of Waterloo Chemical Physics Research Program Report No. CP-555R, 2000 (unpublished).

${ }^{29}$ D. Bellert and W. H. Breckenridge, Chem. Rev. (Washington, D.C.) 102, 1595 (2002). and references therein.

${ }^{30}$ W. H. Breckenridge, V. L. Ayles, and T. G. Wright, Chem. Phys. 333, 77 (2007).

${ }^{31}$ J. P. Read and A. D. Buckingham, J. Am. Chem. Soc. 119, 9010 (1997).

${ }^{32}$ W. H. Breckenridge, V. L. Ayles, and T. G. Wright (unpublished).

${ }^{33}$ L. A. Viehland, Chem. Phys. 179, 71 (1994).

${ }^{34}$ L. A. Viehland, Chem. Phys. 70, 149 (1982).

${ }^{35}$ L. A. Viehland, Chem. Phys. 85, 291 (1984).

${ }^{36}$ H. W. Ellis, R. Y. Pai, E. W. McDaniel, E. A. Mason, and L. A. Viehland, At. Data Nucl. Data Tables 17, 177 (1976).

${ }^{37}$ H. W. Ellis, E. W. McDaniel, D. L. Albritton, L. A. Viehland, S. L. Lin, and E. A. Mason, At. Data Nucl. Data Tables 22, 17 (1978).

${ }^{38}$ H. W. Ellis, M. G. Thackston, E. W. McDaniel, and E. A. Mason, At. Data Nucl. Data Tables 31, 113 (1984).

${ }^{39}$ L. A. Viehland and E. A. Mason, At. Data Nucl. Data Tables 60, 37 (1995).

${ }^{40}$ L. A. Viehland and C. C. Kirkpatrick, Int. J. Mass Spectrom. Ion Process. 149/150, 555 (1995).

${ }^{41}$ To access this database you must telnet to the computer named sassafrass. chatham. edu and login as gastrans. The required password will be provided upon request by e-mail to viehland@chatham. edu.

${ }^{42}$ I. Dotan, W. Lindinger, and D. L. Albritton, J. Chem. Phys. 64, 4544 (1976).

${ }^{43}$ L. A. Viehland, E. A. Mason, W. F. Morrison, and M. R. Flannery, At. Data Nucl. Data Tables 16, 495 (1975).

${ }^{44}$ G. A. Eiceman and Z. Karpa, Ion Mobility Spectrometry, 2nd Ed. (Taylor \& Francis, Boca Roton, FL, 2005).

${ }^{45}$ H. E. Revercomb and E. A. Mason, Anal. Chem. 47, 970 (1975).

${ }^{46}$ G. H. Wannier, Bell Syst. Tech. J. 32, 170 (1953). 